\title{
GUEST EDITORIAL Nuclear War and the Environment
}

$\mathrm{T}$ he greatest turning-point* in human history occurred in a remote corner of New Mexico on 16 July 1945 , when the first nuclear bomb was set off. It was not in the Garden of Eden, but in the Desert of Sonora, that our species lost its innocence. This awesome physical tour de force gave us unprecedented powers of instantaneous destruction, almost immediately to be horribly demonstrated twice over.

The inexorable subsequent advances in the technology of nuclear weapons and their delivery systems, and the similarly inexorable subsequent swelling of US and Soviet nuclear arsenals, have now together provided us with the cheerless ability to destroy ourselves. Albert Einstein captured our terrible dilemma succinctly in 1946 when he observed that 'The unleashed power of the atom has changed everything save our modes of thinking and we thus drift toward unparalleled catastrophe'.

The immediate devastation that would be inflicted upon the land and people of both the USA and USSR - were these two 'superpowers' to engage in a major nuclear war (and even a limited nuclear war can be expected to escalate to a major one) - can be scientifically predicted in objective terms, but nevertheless is simply too great to be truly grasped. The relatively few US and Soviet survivors would face a blighted environment in which their societal infrastructures would have been obliterated-including many of their large cities, their national and international communication-systems, most of their medical facilities, their ability to pursue mechanized agriculture, their administrative and governance hierarchies, and, of course, such other amenities of life as their educational systems and the artefacts that comprise their cultural heritages.

The land and people of those nations allied to the two superpowers would, of course, also bear some greater or lesser fraction of the direct brunt of such a war. Indeed, some nations of central Europe would quite likely be obliterated.

One of the real tragedies of a major nuclear war is that its horrible impact would not be confined either in time or in space. The devastated human environment-urban, agricultural, and natural-with which the survivors of the directly-embroiled nations and their subsequent offspring would have to cope in the postwar decades, would add untold hardship to their lives.

In some respects sadder yet would be the adverse impact on hundreds of millions of people in the many uninvolved nations. The environment upon which these huge numbers of people must depend for their sustenance would be sure to become compromised in several important ways. They would for many years be unavoidably exposed to greater or lesser amounts of radionuclides. They, and the fauna and flora, would perhaps also have to endure several years of dangerously enhanced ultraviolet radiation. They might well also experience several months of adverse weather conditions-including, especially, conditions of reduced light and thus of temperature - to the extent that their agricultural production would be threatened and that the natural ecosystems would be severely damaged.

\section{Five Unequal Deterrents}

A nuclear war between the two superpowers has been avoided thus far owing to the following five, albeit unequally important, factors: (1) no sufficiently grave provocation or political rationalization ('justification') by either of the two sides to initiate such a war; (2) the ability of neither of the two sides to attack the other with sufficient might and skill to preclude a devastating response; (3) the possibility that collateral degradation of the human environment might be sufficiently severe and widespread to 'backfire' to an unacceptable level; (4) the notion that to inflict such a level of carnage upon an adversary nation or nations (as well as lesser amounts on bystander nations) would be immoral or depraved; and (5) the fact that warning mechanisms have been sufficiently reliable and isolated from unauthorized madmen to prevent false signals of a nuclear attack that would then initiate a real response and counter-response.

Three of these five factors that have thus far saved us from a nuclear war appear not to have changed much in recent years, and to me appear unlikely to do so in at least the coming few years. These 'brakes' of more or less stable relative importance are an insufficient amount of provocation or excuse (No. 1), a sufficientlydeveloped sense of morality or propriety (No. 4), and a sufficiently reliable system of safeguards to prevent an unintended holocaust (No. 5). Of the remaining two preventive factors, one (No. 2) gives me reason for ever-heightened anxiety, whereas the other (No. 3) provides some reason for modest hope.

* Professor Westing's considered opinion with which we do not necessarily agree, as we feel that our No. 1 objective should be to prevent it from ever proving to have been so. - Ed. 
The nuclear arms-race between the two superpowers continues unabated in both quantitative and qualitative terms. The US stockpile of nuclear weapons, already numbering in the many thousands, continues to grow by several per week; and the Soviet situation is presumably comparable. But of even more profound concern is the fact that missile accuracy continues to be improved upon, as does the ability to locate a potential enemy's submarine missile-launchers. Although there is no possibility of developing an adequate defence against incoming missiles, these latter 'advances' by the USA, and presumably by the USSR as well, are nevertheless coming ever-closer to invalidating the present state of stable deterrence-that is, the present state of mutually assured destruction in the event that either of the two sides should have the temerity to strike first. I fear that it may now be only a matter of years before one of the two superpowers comes to believe that it has attained the ability to make a first strike without fear of 'unacceptable' retaliation. I tremble to think of what might happen if once this capability were perceived to have been attained by one of the superpowers, or if its imminent attainment were anticipated by the other.

\section{A Modest Hope}

The one modest note of optimism that can be struck in this grim nuclear litany turns out to be an environmental matter. Thus there is a growing perception that a major nuclear war could lead to serious environmental (atmospheric) disruption of hemispheric dimensions for a period of some months. This rather newly-suggested possibility of so-called 'nuclear winter' might be sufficiently severe and widespread to insure that a major attack would backfire-that is, might even in effect be an act of national suicide. It is only reasonable to suppose that a recognition of this possibility will act as yet another potent disincentive to initiate a nuclear war. It thus falls upon scientists of both East and West to investigate further-and publicize - the adverse environmental effects of a possible nuclear war. Let us hope that in this way the balance becomes more clearly and firmly tipped in favour of social and ecological sanity.

Arthur H. Westing, Senior Research Fellow

Stockholm International Peace Research Institute

Pipers Väg 28

S-17 173 Solna

Sweden;

Adjunct Professor of Ecology (formerly Dean of Natural Science)

Hampshire College

Amherst, Massachusetts, USA. 